\title{
Effect of Thiourea on the Nanocrystalline-Copper Coating Prepared by Jet Electrodeposition
}

\author{
Hui Fan ${ }^{1 *}$, Sainan Cao ${ }^{2}$, Yangpei Zhao ${ }^{3}$, Shankui Wang ${ }^{1}$ \\ ${ }^{1}$ School of Mechanical and Electrical Engineering, Jiangsu Normal University, Xuzhou, 221116, \\ China; \\ ${ }^{2}$ Jiangsu Key Laboratory of 3D Printing Equipment and Application Technology, Nantong Institute of \\ Technology, Nantong, 226002, China; \\ ${ }^{3}$ Jiang su Jiangzhu Institute, Xuzhou, 221116, China \\ *E-mail: xzfanhui@163.com
}

doi: $10.20964 / 2019.08 .99$

Received: 6 April 2019 / Accepted: 14 June 2019 / Published: 30 June 2019

Jet electrodeposition with the aid of thiourea was proposed in this paper to improve the deposition quality of copper coatings. The effects of the content in the electrolyte on the coating microstructures, morphologies and mechanical performances were examined. The results show that a dense nanocrystalline copper coating is fabricated with $10 \mathrm{mg} / \mathrm{L}$ thiourea addition. The average crystal size attains $29 \mathrm{~nm}$. The preferred crystal orientation varies from (111) to (220) as the thiourea content in the electrolyte rises to $10 \mathrm{mg} / \mathrm{L}$ from $5 \mathrm{mg} / \mathrm{L}$. The microhardness increases by $81 \%$, and the tensile strength increases by $51 \%$, using current density $400 \mathrm{~A} / \mathrm{dm}^{2}$ and at the thiourea concentration $10 \mathrm{mg} / \mathrm{L}$.

Keywords: thiourea; jet electrodeposition; coating microstructures; properties

\section{FULL TEXT}

(C) 2019 The Authors. Published by ESG (www.electrochemsci.org). This article is an open access article distributed under the terms and conditions of the Creative Commons Attribution license (http://creativecommons.org/licenses/by/4.0/). 